\title{
On the influence of second use, future battery technologies, and battery lifetime on the maximum recycled content of future electric vehicle batteries in Europe
}

(1)

\author{
Mohammad Abdelbaky*, Jef R. Peeters, Wim Dewulf
}

KU Leuven, Department of Mechanical Engineering, Celestijnenlaan 300A, BOX 2422, 3001, Leuven,

Belgium

* Corresponding author. E-mail address: mohammad.abdelbaky@ kuleuven.be

\section{Abstract}

The European Union is promoting the uptake of low emission vehicles to reduce greenhouse gas emissions from transportation. However, this transition will increase the demand for five important battery raw materials; i.e. lithium, nickel, cobalt, copper, and graphite. Therefore, a substance flow analysis and forecasting model are proposed to investigate the flow of these materials through the different lifecycle stages of electric vehicle batteries. The model forecasts that by 2040 , the vehicle stock will be from 72 to 78 million vehicles, while the second use stock will be from 3 to 11 million batteries. In addition, the annual recycling waste stream in 2040 will grow to roughly 3 million batteries with a capacity of $125 \mathrm{GWh}$. Results indicate that this waste stream could cover between $10 \%$ and $300 \%$ of future raw materials demand for electric vehicles. The width of this range is dominated by uncertainties on the rapidly evolving material composition of automotive batteries and the possible commercialization of cobalt-free battery technologies. The remaining uncertainty is attributed to the battery lifetime in vehicle use and potential second use of retired batteries. Keywords: Substance flow analysis; Waste stream forecasting; Electric vehicle batteries; sensitivity analysis;

\section{Introduction}

The global market for rechargeable batteries is growing annually and is projected to reach $1000 \mathrm{GWh}$ in 2025 (Pillot, 2019). In addition, the European Union (EU) launched the European Battery Alliance (EBA) industrial policy in 2017 to stimulate battery production in Europe and match the increasing investments in vehicle electrification by automotive manufacturers (European Comission, 2018a). The lithium ion battery (LIB) is a versatile rechargeable battery that has a high potential for a wide range of applications. Between 2010 and 2018, the global cell production of LIBs witnessed an annual increase of $26 \%$, with only $3 \%$ 
27 produced in Europe (Tsiropoulos, et al., 2018).

28 LIBs are a key enabler for electric vehicles because of their slow self-discharge rate, high energy density, 29 and lack of memory effect (Li, et al., 2019). Moreover, LIBs offer a sustainable solution for electric vehicles 30 provided that a low carbon electricity mix is used for charging and battery waste is recycled (Ellingsen, et 31 al., 2016; Mohr, et al., 2020). It is estimated that electric mobility represented $60 \%$ of the global LIB cell 32 production in 2018 (Pillot, 2019). In 2019, the number of newly registered EVs exceeded two million vehicles 33 worldwide (Kane, 2020). According to outlook studies from the International Energy Agency (IEA) and 34 Deloitte LLP, global EV sales will reach 21 million vehicles by 2030 (Walton, et al., 2019; IEA, 2018). Key 35 factors that will boost EV sales include the development of a charging infrastructure, and a reduction of total 36 cost of ownership of battery electric vehicles (BEVs) to the level of internal combustion engine vehicles 37 (Plananska, 2020; Walton, et al., 2019). The IEA defines the latter parity at a battery price of $120 \mathrm{US} \$ / \mathrm{kWh}$ combined with a gasoline price of 1.5 US\$/liter (IEA, 2018). LIBs on the market today have specific costs in 39 the order of $200 \mathrm{US} \$ / \mathrm{kWh}$, and an 18\% technology learning rate (Goldie-Scot, 2019; IEA, 2018).

$40 \quad$ For the purpose of lowering cell production costs and improving battery system performance, numerous 41 cell chemistries emerged over the last decades. First, early EV models used cells with lithium cobalt oxide 42 (LCO) cathodes because of their low self-discharge, high discharge voltage, and high reversible capacity 43 (Nitta, et al., 2015). Nevertheless, LCO cathodes suffer from low thermal stability, rapid fade of capacity at 44 high current rates, short life span, and limited load capabilities (Nitta, et al., 2015). Second, car and bus 45 manufacturers use cells with lithium iron phosphate (LFP) cathodes due to their inherent safety, long cycle46 lifetime, and resource availability, while key disadvantages are poor lithium diffusion, low voltage, and poor 47 electronic conductivity (Anseán, et al., 2013). Third, the Lithium Manganese Oxide (LMO) spinel cathode is 48 used in EV battery cells due to its low internal cell resistance, capability of high current discharging and fast 49 charging, and use of manganese that is cheaper than cobalt (Miao, et al., 2019; Nitta, et al., 2015). 50 Furthermore, the performance of LMO cathodes is upgraded by blending with Lithium Nickel Manganese 
51 Cobalt oxides (LMO blend) (Miao, et al., 2019). At present, Lithium Nickel Manganese Cobalt Oxides 52 (NMC) and Lithium Nickel Cobalt Aluminum Oxide (NCA) are the cathode chemistries with the largest 53 market share in lightweight commercial and passenger electric vehicles in Europe (Tsiropoulos, et al., 2018).

$54 \mathrm{NMC}$ batteries on the market have the general chemical formula $\mathrm{LiNi}_{10-x-y} \mathrm{Co}_{x} \mathrm{Mn}_{y} \mathrm{O}_{2}$ and use a 1:1:1, 4:2:4, $55 \quad 5: 3: 2$, or 6:2:2 ratio for nickel, manganese, and cobalt, respectively.

56 In recent years, research on novel energy dense cell chemistries has intensified. High energy content NMC 57811 cells will soon enter the market (Olivetti, et al., 2017). Next generation advanced lithium ion batteries, 58 as termed by the IEA, use solid polymers as electrolytes to provide higher densities and safer performance 59 while exhibiting a minimal to no content of cobalt and graphite in the electrodes (IEA, 2018). Additionally, 60 lithium-air and lithium-sulfur batteries, or Beyond lithium-ion batteries, are anticipated to enter the EV 61 market by 2030 (IEA, 2018). The electrodes of Beyond lithium-ion batteries operate with reconstitution 62 reactions and can provide between 5 and 10 times more energy storage capacity than LIBs (Rahman, et al., 63 2014).

64 On the one hand, several studies argue that battery second use has an important role in extending battery 65 lifetime, reducing their ownership costs, and mitigating environmental impacts as opposed to vehicle use 66 followed by direct recycling (Canals Casals, et al., 2019; Bobba, et al., 2018; Canals Casals, et al., 2016; 67 Debnath, et al., 2014). To this end, pilot scale plants in France, Germany, and the Netherlands are utilizing 68 retired EV batteries in stationary energy storage applications (B2U) (Bobba, et al., 2018). On the other hand, 69 B2U may complicate the reverse logistics of EV batteries and delay their eventual collection for recycling. 70 Furthermore, the export of conventional vehicles and low collection rates of electronic waste suggests low 71 collection rates for retired EV batteries (Eurostat, 2019; Mehlhart, et al., 2017). However, experts at the 24 ${ }^{\text {th }}$ 72 international congress for battery recycling reported collection rates higher than $90 \%$ for industrial and EV 73 batteries (Gattiglio, 2019; Pillot, 2019).

74 One EV battery may contain several kilograms of lithium, nickel, cobalt, copper, and graphite depending 
on its energy storage capacity and cell chemistry. Therefore, it is anticipated that the increase in raw material demands from the EV market will create short term bottlenecks in lithium and battery grade nickel supplies and long term excess copper demand (European Comission, 2018b; Elshkaki, et al., 2016). In addition, lithium, cobalt, and natural graphite are classified as critical raw materials for the European Union, and nickel is closely monitored due to the growing demand for battery production (European Commission, 2020). Therefore, the EBA defined secure access to secondary battery materials as a pillar of its action plan and is supporting pan-European research on developing sustainable and environmentally friendly recycling processes (European Commission, 2019; European Comission, 2018a).

Management of obsolete electric vehicles is of utmost importance and has received considerable attention in research (D'Adamo \& Rosa, 2019). Furthermore, estimates for the future EV battery waste stream may steer process developments and expansion plans for second use and recycling infrastructure. Due to the long lifetime of batteries in EV use, forecasts for the EV battery waste stream that go beyond 2030 are needed to manage the more significant part of the waste stream that is associated with EV sales between 2020 and 2030. Most prior studies consider only one scenario in their forecasts and limit the time horizon of their forecasting models to 2030 (Bobba, et al., 2019; Kelleher Environmental, 2019; Xu, et al., 2017). As a result, previous studies have not dealt with battery technology developments and their effect on the waste stream recycling potential and the extent to which the recycling industry could fulfil future raw materials demand.

$$
\text { In this article, a forecasting model is presented for the generation of battery waste from lightweight }
$$
commercial and passenger EVs in Europe between 2010 and 2040. First, the study establishes estimates for future EV sales in Europe and the consequent raw materials demand in 2040. Then, a distribution delay forecasting model and a substance flow analysis are formulated to evaluate the recycled content of the 2040 EV battery waste stream and the extent of future demand it can cover. Finally, thorough sensitivity analyses are presented to quantify the uncertainty on amounts of recycled lithium, nickel, cobalt, copper, and graphite and to identify parameters that most influence the forecasting model output. 


\section{Materials and methods}

The next subsections will detail the EV battery lifecycle stages modelled, put on market data, and the forecasting model and substance flow analysis. Subsequently, the sensitivity analysis techniques used to evaluate the total variance of the model output will be presented.

\subsection{Materials}

\subsubsection{Lifecycle stages of an EV battery}

Figure 1 illustrates the lifecycle stages of an EV battery. In the production stage, battery cells are first assembled into modules, and subsequently connected to a battery management system to form the eventual battery assembly used in an EV . Throughout its operational life, the state of health $(\mathrm{SoH})$ of the battery is reduced due to several ageing mechanisms that leads to reduced energy storage capacity, increased internal resistance, and decreased roundtrip energy efficiency. Furthermore, the battery can reach premature end of life due to internal factors, such as component failures and accelerated ageing mechanisms, or external factors, such as road accidents (Early failure). Depending on the magnitude of the early failure, a battery can be repaired, reused, remanufactured in an EV, or otherwise recycled and replaced by a new battery system (Replacement). At a certain threshold value for the SoH (First end of life), EV batteries are then either used in stationary energy storage applications prior to recycling (Repurpose), or recycled to recover valuable metals (Direct recycling).

Formulating a universal battery lifetime model that is representative for all commercial EV batteries is infeasible since the market is shared among various original equipment manufacturers employing different cell chemistries, cooling systems, and management systems. Therefore, the ageing mechanisms in commercial EV batteries will vary due to the difference in cell voltage and operating temperature (Barré, et al., 2013). However, the central limit theorem justifies the use of a normal distribution for the lifetime modelling of all EV batteries produced in one year because the standardized sample mean of their lifetime distributions will tend toward a standard normal distribution (Mathai \& Haubold, 2018). 


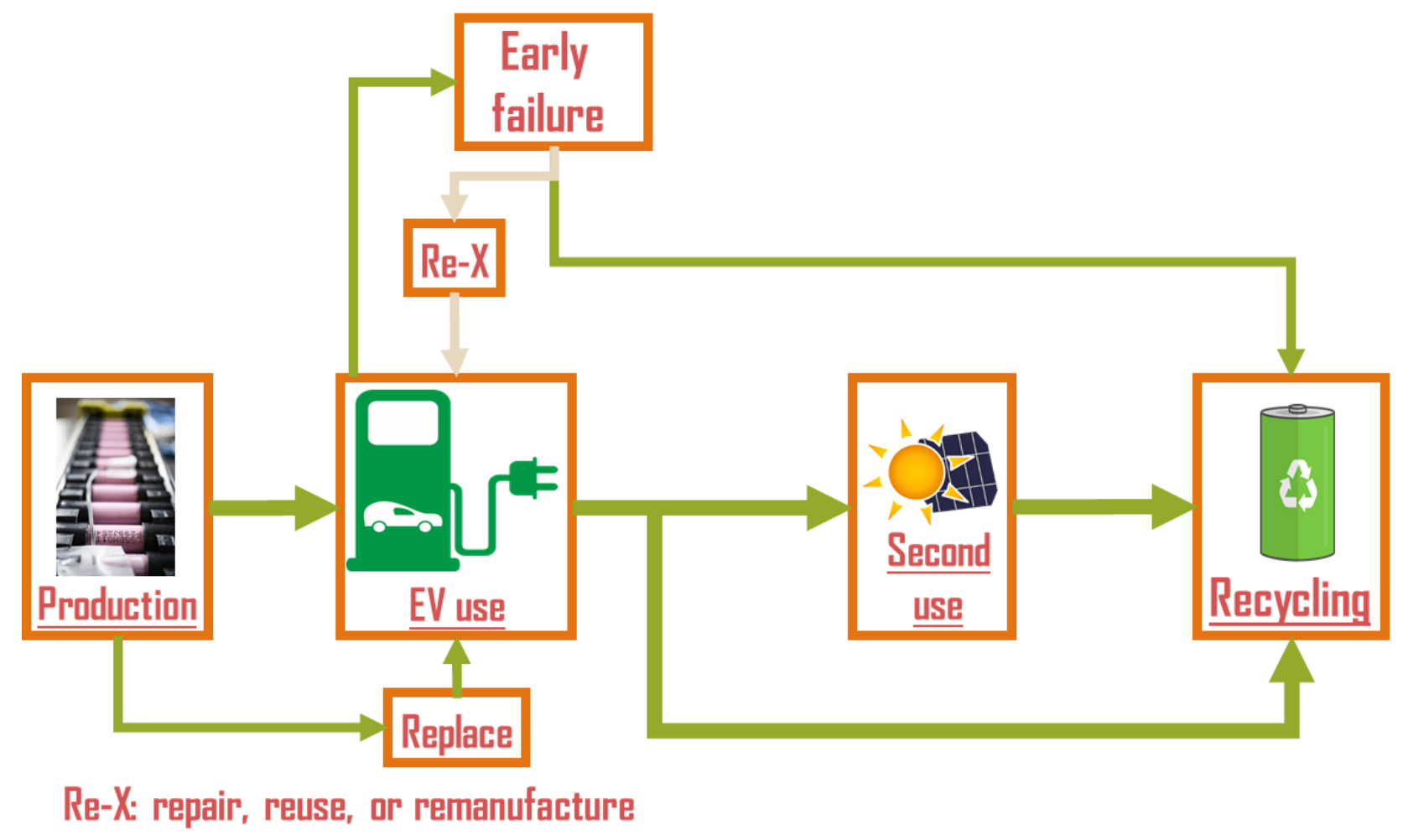

Figure 1: Modelled life cycle stages of an electric vehicle battery

123 The probability density function for battery lifetime in EV use is characterized by the mean lifetime value $124\left(\mu_{E V}\right)$ and its standard deviation $\left(\sigma_{E V}\right)$. The standard deviation is set such that $98 \%$ of the batteries outlast the 1258 years of warranty. Furthermore, two third of the batteries are modeled to end their vehicle lifetime during 126 the expected lifetime in EV use, which may range from 10 to 15 years according to (Bobba, et al., 2019; 127 Neubauer, et al., 2015). The probability density function for battery failure in second use is also defined by 128 the mean lifetime value $\left(\mu_{B 2 U}\right)$ and its standard deviation $\left(\sigma_{B 2 U}\right)$. The standard deviation is set such that at 129 least $85 \%$ of the batteries survive 3 years in a short commercial battery storage application (Jenkins, et al., 130 2008). Additionally, only $15 \%$ of the batteries survive the maximum expected lifetime in second use, which 131 may range from 4 to 10 years (Neubauer, et al., 2015).

\section{2.1.2. Put-on-market battery technologies and their relevant metal content}

133 The number of put on market EV batteries in Europe is derived from the vehicle sales forecast. At the time 134 of writing this article, the authors anticipate the current Covid-19 pandemic situation to influence future EV 
sales. Furthermore, the 2020 Global EV outlook suggests that the pandemic situation may either boost or 136 abate personal car ownership (IEA, 2020). Consequently, the 2030 global electric car stock may deviate by $137 \pm 33 \%$ from the 125 million cars estimate in previous IEA outlook studies. Because it is too early to verify 138 these claims, the study at hand will rely on outlook studies that were published prior to the pandemic situation.

139 The IEA forecasts Europe to maintain its market share of global EV sales at 22\% until 2030 (IEA, 2018).

140 Therefore, annual EV sales in Europe are estimated to reach 2.8 million vehicles in 2025, and 5 million in 1412030 (Walton, et al., 2019; IEA, 2018). By 2040, annual EV sales in Europe will reach to 8 million vehicles. 142 This number is derived by assuming that $50 \%$ of passenger car sales in 2040 will be plug-in electric. The 143 increase in annual EV sales between 2018 and 2030 is modelled using a third order polynomial regression, 144 followed by a linear regression between 2030 and 2040.

145 In this work, the content of relevant materials, i.e. lithium, nickel, cobalt, copper, and graphite, is defined 146 per kWh basis based on projected yearly energy capacities (Table I in the Supplementary Material). The 147 average battery capacity in new BEVs is assumed to increase linearly from $44 \mathrm{kWh}$ in 2018 to $60 \mathrm{kWh}$ in 1482030 , and $82 \mathrm{kWh}$ in 2040. Similarly, the average battery capacity in new plug-in hybrid electric vehicles 149 (PHEVs) is assumed to increase from $10 \mathrm{kWh}$ in 2018 to $15 \mathrm{kWh}$ in 2030, and $20 \mathrm{kWh}$ in 2040. In 2030, $15070 \%$ of new EV sales will be fully electric and $30 \%$ will be plug-in hybrid. From 2030 onwards, the share of $151 \mathrm{BEV}$ and PHEV in new EV sales is presumed constant since no other substantiated projections are available.

\subsection{Methods}

\subsubsection{Substance flow analysis in previous work}

Previous studies have proposed substance flow analysis models to predict the recovery of valuable metals, i.e. lithium, cobalt, iron-neodymium-boron magnets, and gold, from different WEEE streams (Bobba, et al., 2019; Ziemann, et al., 2018; Peeters, et al., 2018; Chancerel, 2010). Substance flow analysis models require data on product sales, lifetime, and/or stock in use. In general, flow analysis models adopt either parametric or non-parametric methods to estimate product lifespan and waste generation. Unlike non-parametric 
approaches, parametric methods assign statistical distribution functions for product lifespan, such as normal,

160 log-normal, or Weibull distributions (Polák \& Drápalová, 2012).

161 Several regional and global studies have forecasted the characteristics of the future waste stream of EV

162 batteries. The study of Bobba et.al on traction LIBs in the EU proposed a truncated lifetime distribution for

163 vehicle use, where only $10 \%$ of the batteries have a lifetime longer than 10 years, and a fixed lifetime in

164 second use that is either 5 or 12 years (Bobba, et al., 2019). Likewise, (Drabik \& Rizos, 2018) assumed a

165 fixed lifetime of 8 years for first use and 10 years for second use (Drabik \& Rizos, 2018). Further regional

166 and global studies employed either truncated lifetime functions for EV use phase duration, or system

167 dynamics modelling of new EV battery increments and scrap generation (Kelleher Environmental, 2019;

168 Ziemann, et al., 2018; Xu, et al., 2017; Richa, et al., 2014).

169 All cited studies rely on different expectations for the market share of cell chemistries in future EV sales,

170 and as a result yield highly variable estimates for the recycling potential of the waste stream. This study

171 considers several scenarios to account for the uncertainty in the share of different cell chemistries in future

172 EV sales. In addition, the battery lifespan in EV use is modelled using a parametric with an independent

173 lifetime distribution. For a given allocation factor for second use of retired EV batteries, the output of the

174 first use lifetime distribution serves as input for a second independent lifetime distribution. Hence, the annual

175 EV battery waste generation potential will consist of direct and indirect battery returns from first use and 176 second use, respectively.

\subsubsection{The distribution delay forecasting model and the underlying substance flow analysis}

181 standard deviation in years. The constant $d$ has a value of $0.65 \%$, and accounts for the annual rate of external

182 failures due to road accidents (Neubauer, et al., 2015). The probability of product failure in the first year of 
the use stage and from the second year onwards are computed as shown in equations 1 and 2 respectively.

$$
\begin{gathered}
D_{u}(s, w)=\Phi\left(\left((w-s)-\mu_{u}\right) / \sigma_{u}\right)+d=1 / 2\left[\operatorname{erf}\left(\frac{(w-s)-\mu_{u}}{\sigma_{u} \sqrt{2}}\right)\right]+d \\
D_{u}(s, w)=\Phi\left(\left((w-s)-\mu_{u}\right) / \sigma_{u}\right)-\Phi\left(\left((w-1-s)-\mu_{u}\right) / \sigma_{u}\right)+d \\
=1 / 2\left[\operatorname{erf}\left(\left((w-s)-\mu_{u}\right) / \sigma_{u} \sqrt{2}\right)-\operatorname{erf}\left(\left((w-1-s)-\mu_{u}\right) / \sigma_{u} \sqrt{2}\right)\right]+d
\end{gathered}
$$

mass fraction of material $i(\mathrm{~kg} / \mathrm{kWh})$ in commercialized EV batteries sold in year $s . r(w)$ is the share of early

188 failures of batteries during the warranty period that can be remanufactured, and $S(w)$ is the share of recycling

in EoL markets. $M_{B E V}(s)$ is the share of BEV sales from all EV sales in year $s$, and $\operatorname{Cap}_{B E V}(s)$ is their average

190 capacity in $\mathrm{kWh}$. Likewise, $M_{P H E V}(s)$ is the share of PHEV sales from all EV sales in year $s$, and $\operatorname{Cap}_{P H E V}(s)$

191 is their average battery capacity in $\mathrm{kWh}$.

$$
\begin{aligned}
& F_{\text {recycling }}(w, i) \\
& \qquad \sum_{1}^{s=w-1} Q P(s) * D_{E V}(s, w) *(1-r(w)) * S(w) *\left(M_{B E V}(s) * \operatorname{Cap}_{B E V}(s)\right. \\
& \left.+M_{P H E V}(s) * \operatorname{Cap}_{P H E V}(s)\right) * C_{i}(s) \\
& Q_{B 2 U}(w)=\sum_{1}^{s=w-1} Q P(s) * D_{E V}(s, w) *(1-r(w)) *(1-S(w))
\end{aligned}
$$

Second use applications and replacement EV batteries are indirect sources of waste EV batteries to recycling. Similarly, the composition of retired $\mathrm{EV}$ batteries from B2U applications $F C_{E O L, B 2 U}(w)$, is

194 formulated as shown in equation 5. The amount of replacements, $Q R(s, w)$, at year $w$ for batteries sold in 195 year $s$, and the rate for early failure replacement $R(w)$ are related, as shown in equation 6. 


$$
\begin{gathered}
F C_{E O L, B 2 U}(w)=\sum_{1}^{s=w-1} Q_{B 2 U}(s) * D_{B 2 U}(s, w) *\left(M_{B E V}(s) * \operatorname{Cap}_{B E V}(s)+M_{P H E V}(s)\right. \\
\left.* \operatorname{Cap}_{P H E V}(s)\right) \\
Q R(s, w)=\sum_{1}^{s=w-1} Q P(s) * D_{E V}(s, w) *(1-r(w)) * R(w)
\end{gathered}
$$

\subsubsection{Scenario based sensitivity analysis: future put on the market technologies and parameters of lifetime distribution}

The effect of the battery lifetime model and of the introduction of future technologies to the EV market is first investigated in a scenario-based sensitivity analysis. A baseline and two extreme scenarios for the share of battery technologies in future European EV sales are considered. The baseline scenario builds on the commercialization dates of future technologies and the 2030 technology mix of the new policies scenario from the IEA outlook study (IEA, 2018). The early adopters scenario considers a faster evolution toward cobalt free battery technologies in automotive applications. The cobalt dependent scenario is based on outlook studies that solely consider cobalt-based technologies to be present in future BEV and PHEV models. The share of battery technologies in forecasted EV sales for these three scenarios is summarized in Figure I in the Supplementary Material.

Three additional reverse logistic schemes are developed for the scenario-based sensitivity analysis considering the uncertainty in the forecasting model parameters. On the one hand, the maximum recycling combines a shorter lifetime for EV batteries, low repair and remanufacturing rates, and higher direct recycling activity at the end of EV use stage. Hence, this scheme will yield the highest recycling capacity needs and recycling potential of the waste stream. On the other hand, the maximum second use scheme combines the longest battery lifetime in both EV and second use, high repair and remanufacturing rates, as well as most B2U applications and least direct recycling at the end of EV use stage. Therefore, the maximum second use scheme yields the lowest waste stream recycling potential due to the delayed return of EV batteries to recycling. Finally, the average scheme is formulated with averaged values from the two schemes mentioned 
215 earlier. Section 6.4. in the Supplementary Material elaborates the basis for building each reverse logistics 216 scheme.

\section{2.2.4. Monte Carlo based sensitivity analysis}

218 A Monte Carlo simulation is executed with the aim of obtaining a better understanding of the uncertainty

219 on the waste stream recycling potential from the five relevant elements, potential overlaps with future raw 220 materials demand, and the effect of uncertainties associated with projected future estimates. As shown in 221 section 2.2.2, the lifetime distribution is based on seven parameters and the uncertainty on future battery 222 technology sales, which affects the estimated material composition per $\mathrm{kWh}$. As a result, a total of eight 223 parameters with high uncertainty modelled as triangular distributions for each relevant recycling material.

224 Next, 10,000 values for the eight parameters are generated and afterwards randomly sampled to evaluate the 225 yearly waste stream recycling potential. Similarly, triangular distributions are derived for the demand of 226 relevant recycling material. The ranges used for different parameters are listed in Table II in the 227 Supplementary Material.

\subsubsection{Variance-based global sensitivity analysis}

229 The used sales scenarios and lifetime distribution parameters yield a wide range of results for the waste 230 stream recycling potential of relevant elements. Therefore, to identify the main parameters whose 231 uncertainties have the strongest influence on the waste stream recycling potential in 2040, the Sobol global 232 variance-based sensitivity analysis method is used (Sobol, 1990). Calculations of the Sobol method are done 233 using the open source SALib sensitivity analysis python library and the embedded Saltelli sampling method 234 (Herman \& Usher, 2017).

235 The Sobol method starts from the orthogonal decomposition of model output $Y$ with its input parameter 236 set $\left(x_{1}, x_{2}, \ldots, x_{n}\right)$ as in equation 6 (Saltelli, et al., 2010). For all input parameters, values are scaled between $237 \quad 0$ and 1. 


$$
Y=f_{0}+\sum_{i=1}^{n} f_{i}\left(x_{i}\right)+\sum_{i=1}^{n-1} \sum_{j=i+1}^{n} f_{i, j}\left(x_{i}, x_{j}\right)+\ldots+f_{12 \ldots n}\left(x_{1}, x_{2}, \ldots, x_{n}\right)
$$

The functions $(f)$ are then related to the partial variances $\left(V_{i}, V_{i j}, \ldots\right)$ and the total variance $(V(Y))$ as in 239 equation 8 (Saltelli, et al., 2010).

$$
\begin{gathered}
V_{i}=V\left(f_{i}\left(x_{i}\right)\right) \\
V_{i j}=V\left(f_{i, j}\left(x_{i}, x_{j}\right)\right) \\
V(Y)=\sum_{i=1}^{n} V_{i}+\sum_{i=1}^{n-1} \sum_{j=i+1}^{n} V_{i j}+\ldots+V_{12 \ldots n}
\end{gathered}
$$

Finally, related sensitivity measures are categorized as first order, higher order, and total effect indices

241 (Saltelli, et al., 2010).

First order sensitivity index: $S_{1, i}=V_{i} / V(Y)$

Second (higher) order sensitivity index: $S_{2, i j}=V_{i j} / V(Y)$

Third (higher) order sensitivity index: $S_{3, i j k}=V_{i j k} / V(Y)$

Total effect sensitivity index: $S_{T i}=S_{1, i}+\sum_{j=i+1}^{n} S_{2, i j}+\sum_{j=i+1}^{n-1} \sum_{k=j+1}^{n} S_{3, i j k}+\ldots$

In this study, a sample size $\mathrm{N}=512$ for the input parameter set $(\mathrm{n}=8)$ is constructed from the 7 parameters mentioned in section 2.2, in addition to the average battery content of the relevant recycling element $\left(C_{i}(s)\right)$.

244 Hence, for every element that is relevant for recycling, 9216 model evaluations are required.

\section{3. Results and discussion}

\subsection{Results with scenario-based sensitivity analysis}

The size of the EV battery stock in use and end of life markets are illustrated in Figure 2. As shown in the 248 figure, estimates from the three reverse logistic schemes for the EV stock in use are in the order of 70 million 249 vehicles. In general, the size of the EV stock in use is greater than annual battery returns to recycling and second use by one order of magnitude. In terms of energy storage capacity, the size of the 2040 recycling 


\section{EV battery stock in use}

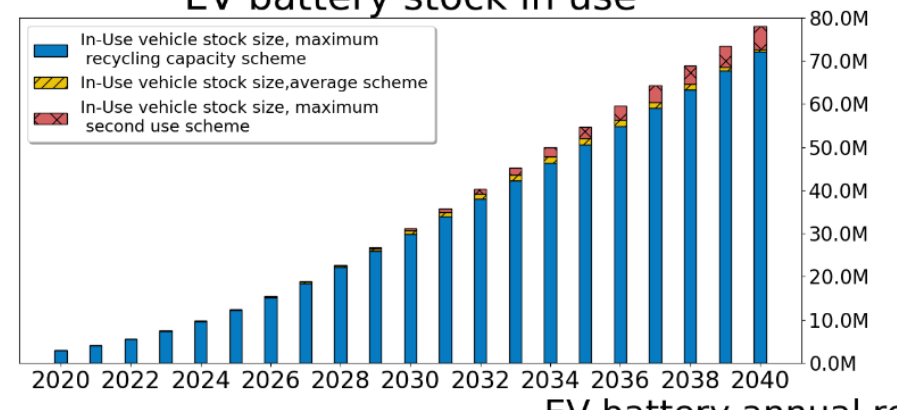

EV battery annual returns to recycling

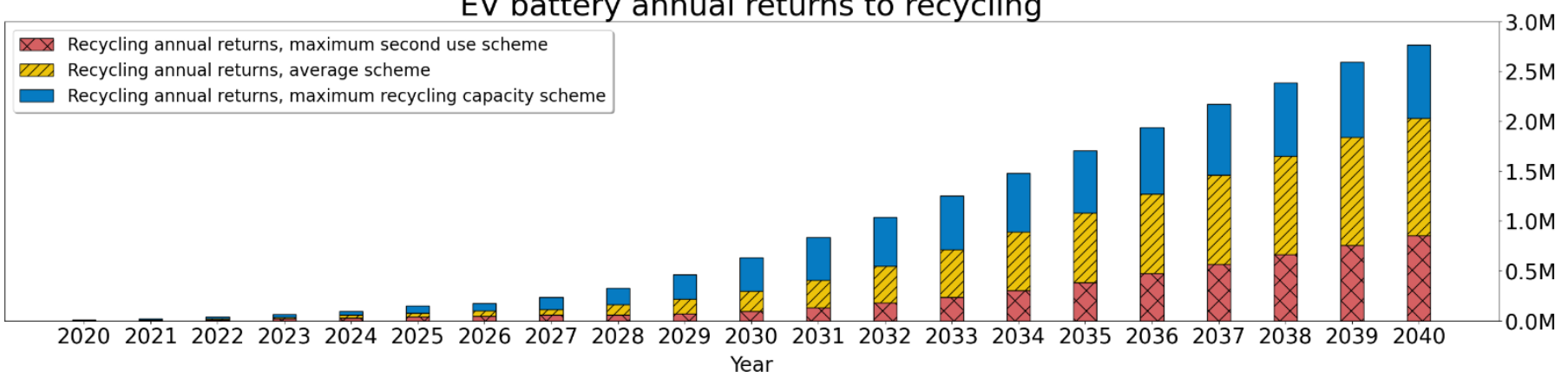

Figure 2: Electric vehicle stock size and returns to end of life markets between 2020 and 2040

stream is only one third of the put on market stream in the same year. This confirms findings from the study

of Melin that the long lifetime of EV batteries is one of the factors responsible for their delayed return to

recycling and the current overcapacity in existing LIB recycling facilities in Europe (Melin, 2019).

The forecasting model with the average scheme of reverse logistics estimates 16.8 million EV batteries to be available for recycling between 2011 and 2040. This signifies that in order to avoid landfilling or exporting of retired EV batteries, recycling facilities with an annual recycling capacity of 340 thousand batteries with a cumulative storage capacity of $10 \mathrm{GWh}$ will be needed in 2030. By 2035, capacity needs will have increased to reach 1.3 million batteries with a cumulative storage capacity of $48 \mathrm{GWh}$, and by 2040 it concerns 3 million batteries with a cumulative storage capacity of $125 \mathrm{GWh}$. Additionally, the maximum recycling capacity scheme yields almost double the amount of waste EV batteries in 2030, and 14\% more in 2040 compared to the average scheme. Likewise, the maximum second use scheme shows that prolonged battery lifetime in use stages enables reducing the returns to recycling by $60 \%$ in 2030 and $40 \%$ in 2040 compared to the average scheme.

The share of different cell chemistries in the EV battery waste stream may vary considerably depending 
on the put on market technologies, and the battery lifetime in first and second use stages. This can be observed from the results of the three sales scenarios used in the forecasting model. For instance, the Baseline sales model with the average reverse logistics scheme estimates a share of $40 \%$ for LMO and LMO blended battery 268 technologies in the recycling waste stream between 2020 and 2025. From 2025 onwards, EV batteries with 269 NMC cathodes will dominate the waste stream. In addition, EV batteries with NCA cathodes are forecasted to be only employed by Tesla, and hence will be present in the product and waste streams with a constant share. For the time horizon of the study, the Baseline sales scenario forecasts that advanced and beyond LIB technologies will marginally contribute to the waste stream. The results are illustrated in Figure 3.

Short battery lifetime in EV use and early adoption of beyond lithium ion technologies in new product sales will yield a waste stream with high shares of NMC 811 and novel technologies by 2040. This is observed in the results of the early adopters sales scenario and the maximum recycling capacity scheme. On the other hand, a waste stream with a large share of NMC 622 and 532 technologies will emerge from long battery lifetime in EV use and from the dependency on cobalt-containing cell technologies.

Based on an $80 \%$ residual storage capacity, the average scheme of reverse logistics estimates that retired EV batteries from the year 2040 alone may potentially provide more than $70 \mathrm{GWh}$ of energy storage capacity in second use applications. Similarly, the maximum second use scheme estimate for second use is $20 \%$ higher than the average scheme, while the estimate from the maximum recycling capacity scheme is $50 \%$ lower. Based on these forecasts, it can be concluded that retired EV batteries could be reused to meet $10 \%$ of the European grid storage capacity requirements for integrating a high share of power generation from variable renewable energy technologies (Cebulla, et al., 2018).

The Baseline scenario and the average scheme forecast the waste stream in 2030 to contain 1.3 ktons of lithium. This is equivalent to $5 \%$ of Europe's demand for lithium for passenger electric vehicles in the same year. In 2040, the lithium content of the waste stream is estimated at $15 \mathrm{ktons}$, which is equivalent to $19 \%$ of the projected demand in 2040. From other sales scenarios and lifetime distributions, the limits for the recycled 


\section{Scenario forecasts for the recycling waste stream technology mix in Europe}

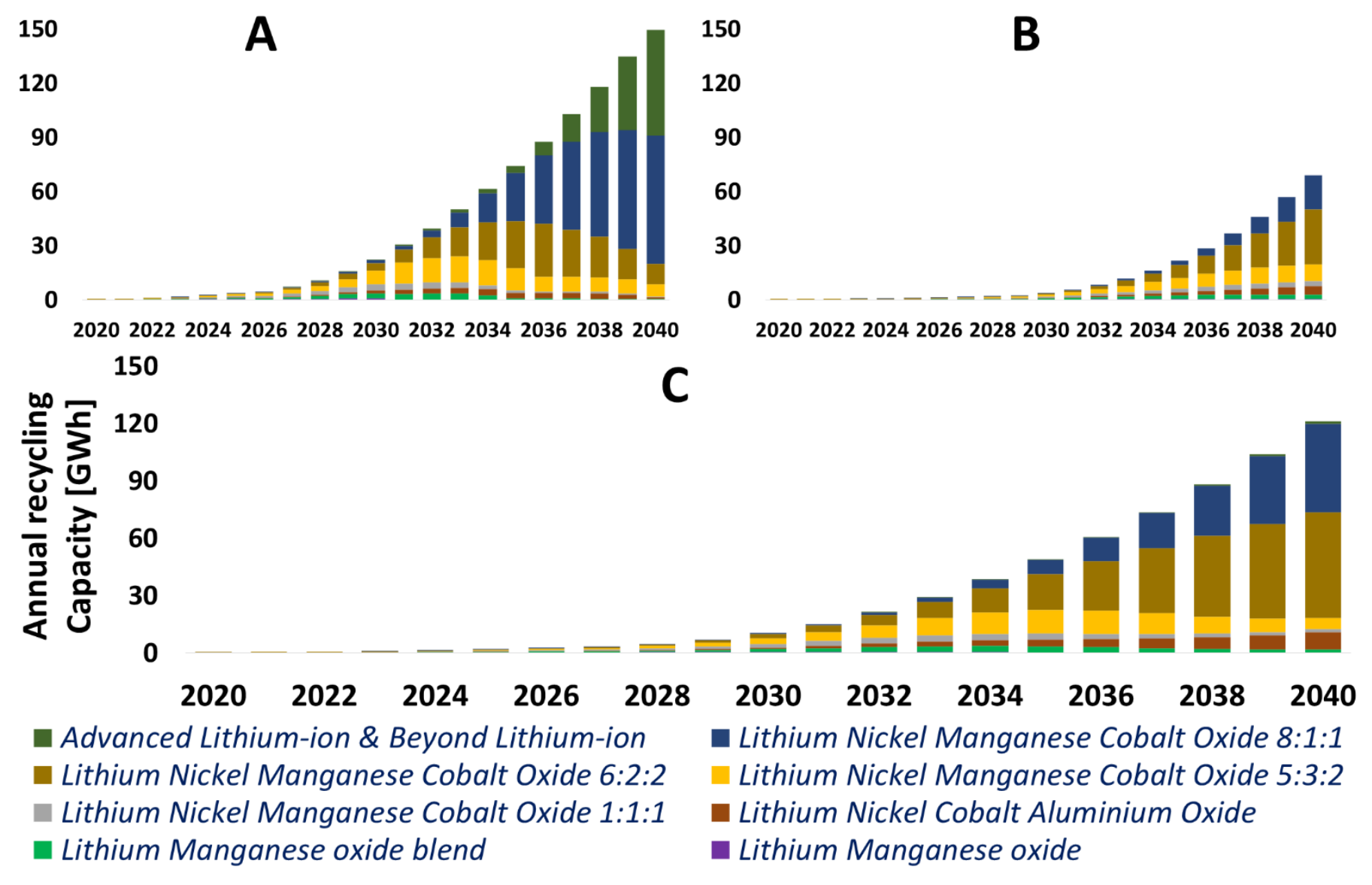

Figure 3: EV battery waste stream annual returns according to cathode chemistry, A: Early adopters sales scenario with the maximum recycling capacity scheme, B: Cobalt dependent scenario with the maximum second use scheme, C: Baseline scenario with the average scheme

lithium potential range from $10 \%$ to $30 \%$ of the demand in 2040. As a result, it is forecasted that EV batteries

will emerge as a major secondary supply for lithium taking into consideration that the global lithium

291 production in 2019 was 77 ktons (U.S. Geological Survey, 2020).

The use of Advanced and Beyond lithium-ion technologies in EVs will play an decisive role in the eventual

waste stream recycling potential. The forecasted 2030 waste stream from the baseline scenario and the average scheme shows a content of 5 ktons of nickel, 2 ktons of cobalt, 11 ktons of graphite, and 8.3 ktons of copper. These estimates are equivalent to only 5\% of Europe's EV sector demand for these metals in the same year. By 2040, however, the cobalt, nickel, graphite, and copper content of recycled EV batteries may 297 fulfil $67 \%, 36 \%, 41 \%$, and $27 \%$ of Europe's EV sector demand for the respective materials. This higher 
potential coverage of raw materials demand by recycling is due to a combination of increased offer of 299 recycled materials and decreased relative share of these materials in novel cathode and anode formulations.

300 Estimates from other scenarios are shown in Figure 4, indicating also a significant uncertainty on the 301 recycling potential.

2040 elements content in recycling stream vs 2040 elements demand

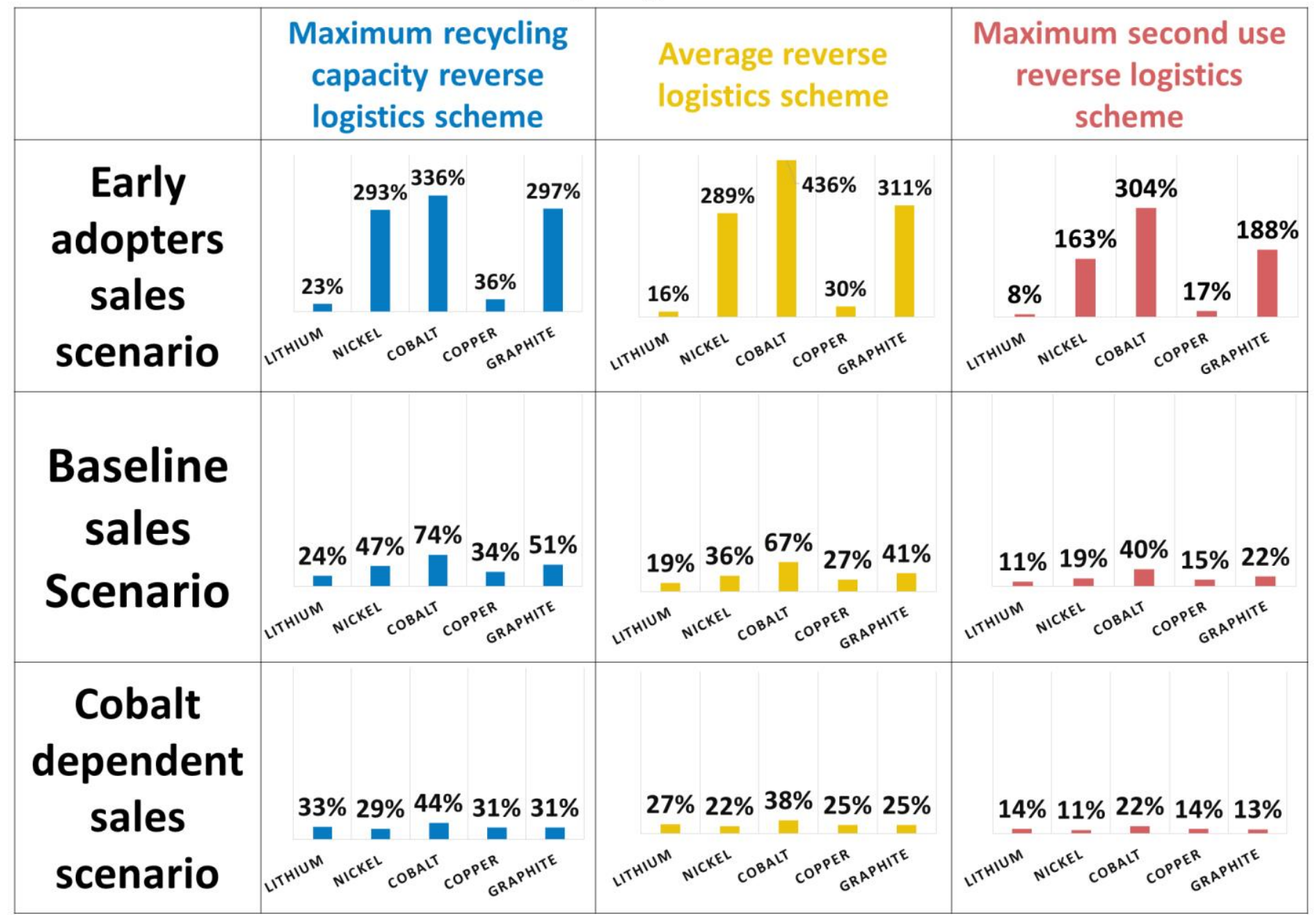

Figure 4: Results of the scenario based sensitivity analysis for elements content in recycled EV batteries compared to Europe's elements demand for EV batteries in 2040

\subsection{Results with Monte Carlo based sensitivity analysis}

As shown in the previous section, results of the early adopters scenario indicate a potential surplus of 304 important secondary material supply for all reverse logistic schemes. Therefore, a Monte Carlo simulation is 
batteries exceeds demand for new batteries, hence leading to open loop recycling of important battery raw 307 materials.

308 As shown in Figure 5, such excess offer of recycled nickel and cobalt from EV battery recycling may 309 occur from 2035 onwards, though the number of parameter combinations yielding such outcome remains

310 limited. Moreover, other end use applications for nickel and cobalt may exploit any unexpected surplus of 311 secondary supply due to a shortfall in demand. With the exclusion of battery end use, the global end use 312 demand for nickel and cobalt in 2019 were 2400 ktons and 95 ktons respectively (U.S. Geological Survey, 313 2020; Nickel Institute, 2019; Azevedo, et al., 2018). These figures are 20 times and 6 times higher than the 314 highest secondary supply estimate for nickel and cobalt in 2040, respectively.

315 For lithium and copper, results do not show any surplus. It is worth noting, though, that the highest estimate 316 for lithium in the 2040 waste stream is 40 ktons, which is 5 times Europe's demand for lithium in 2019 (U.S. 317 Geological Survey, 2020; De Haldevang, 2020). At present, the recovery of lithium from state of the art EV 318 batteries is less awarding in terms of economic feasibility and recycling efficiency compared to nickel and 319 cobalt (Velázquez-Martínez, et al., 2019). For several industrial processes, the quality of recycled lithium is 320 low and cannot be used in cell production. Hence, battery recycling may marginally reduce future lithium 321 demand. Furthermore, open loop recycling of lithium may generate an oversupply of recycled lithium that 322 can only be partially exploited by other sectors. Such findings are also reported by (Ziemann, et al., 2018) 323 who conclude that the global supply of recycled lithium from EV batteries could exceed the demand from 324 other applications. Hence, the expected reduction in the future demand of virgin lithium will be insignificant. 325 For copper, waste stream content can at best cover $40 \%$ of future demand. In addition, there are some 326 concerns about the purity of recycled copper and scrap surplus from open loop recycling. Examples of 


\section{Lithium}

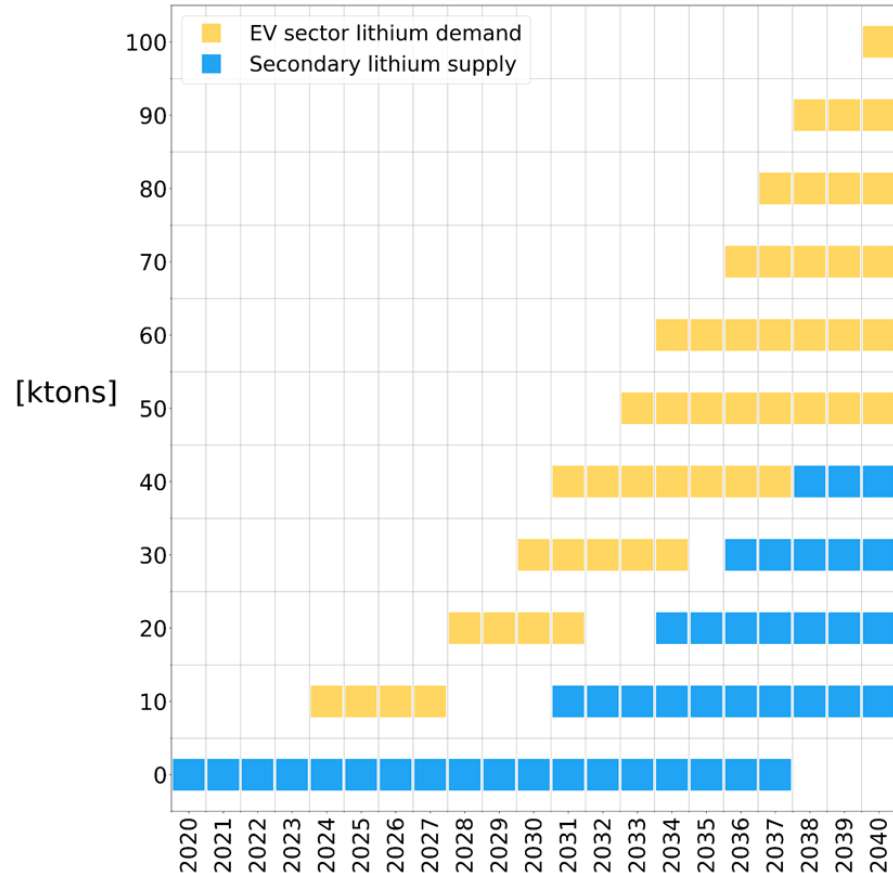

Cobalt

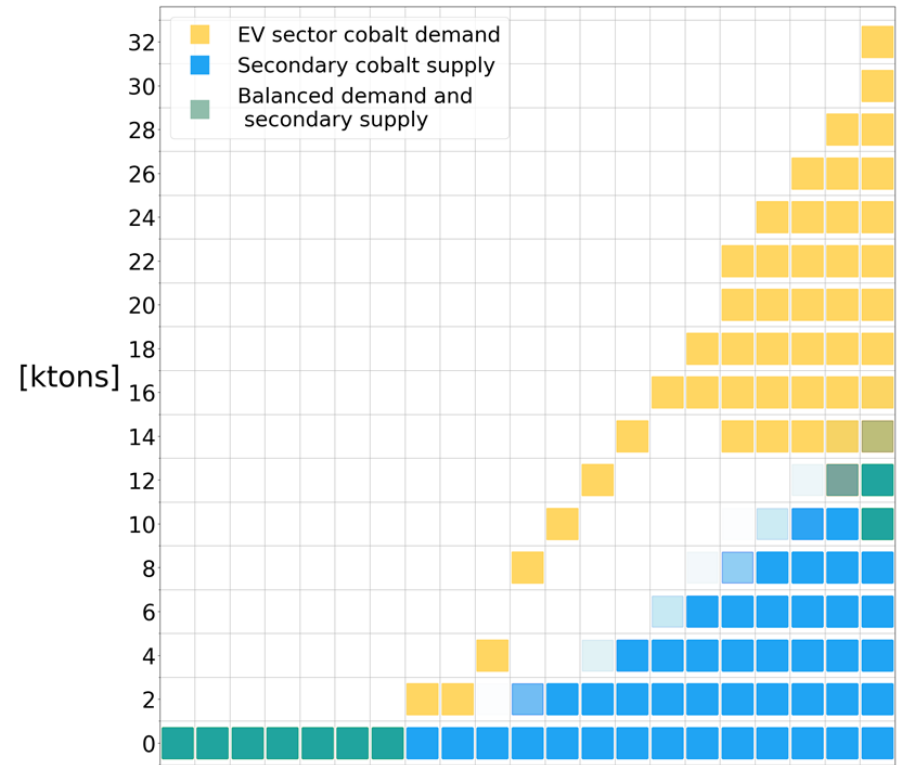

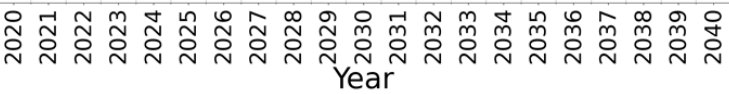

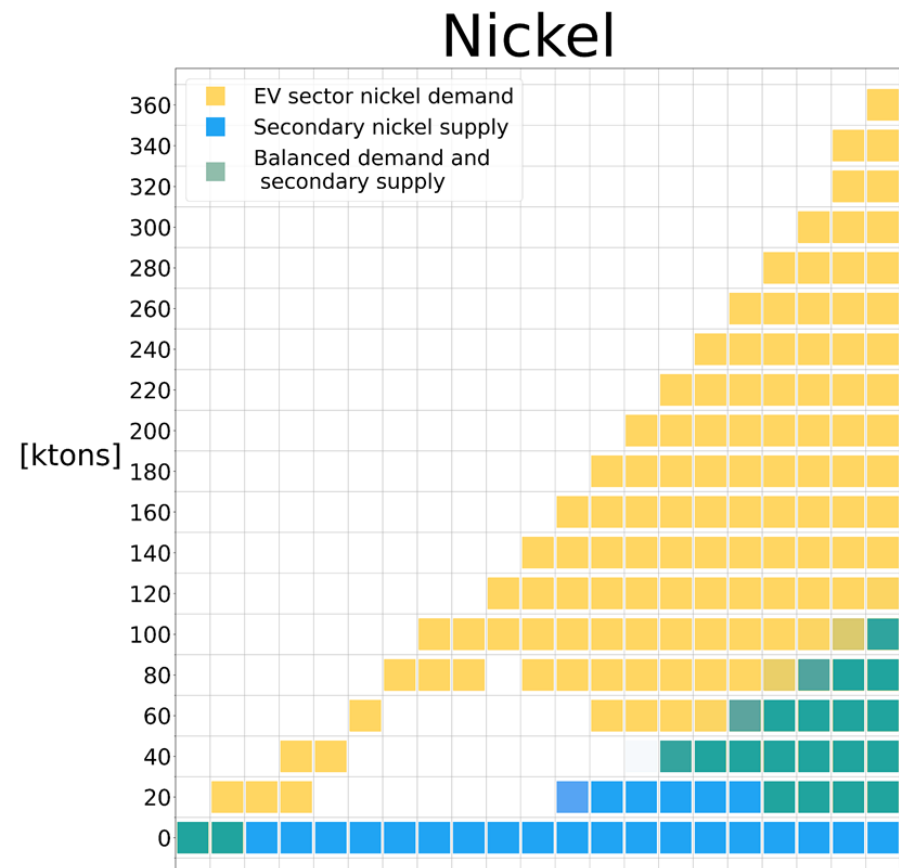

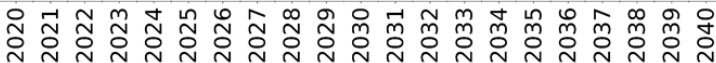

Copper

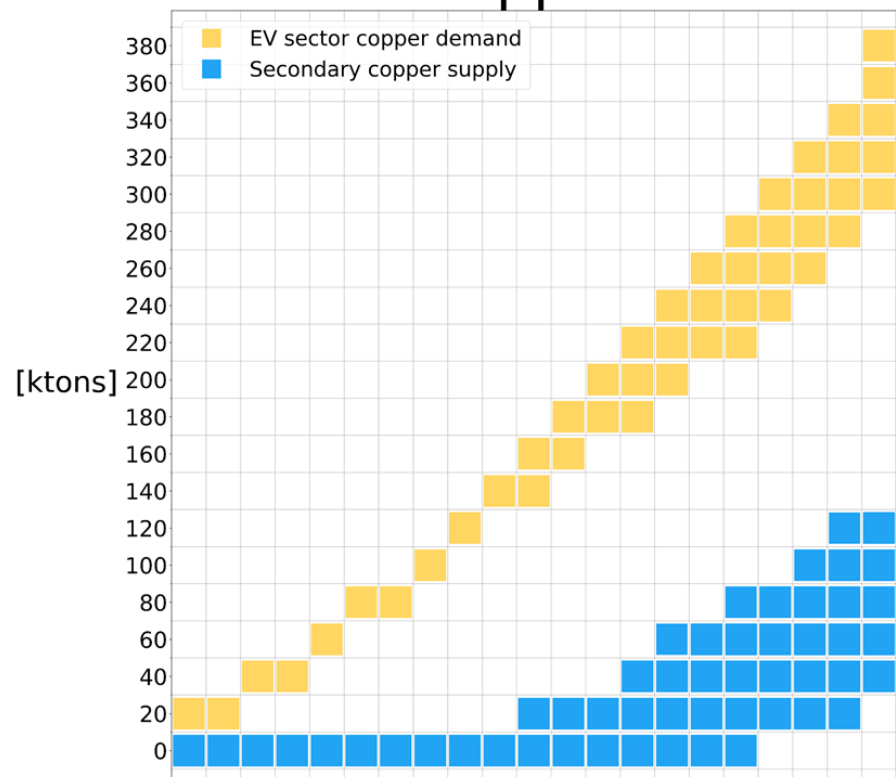

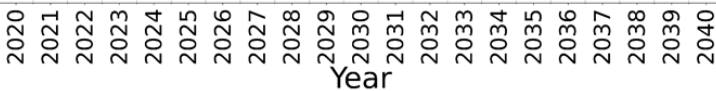

Figure 5: Monte Carlo simulation results for Europe's EV sector future demand and secondary supply of lithium, nickel, cobalt, and copper

established markets for recycled copper are the building and construction, and power generation segments 
328 (Transparency market research, 2020).

\section{3.3. Global sensitivity analysis results}

330 Parameters with the highest values for the first order Sobol indices are listed in Table 1. Results of this

331 global sensitivity analysis demonstrate that $90 \%$ of the total variance in the estimates of the waste stream for

332 lithium, nickel, and cobalt is due to the uncertainty in the future put on market battery technologies and their

333 energy specific metal content. In the case of copper however, the effect of this parameter on the total variance

334 is evaluated at only $58 \%$ due to the lower uncertainty in the specific copper content, which is mostly used as

335 a current collector for the battery anode. This confirms the findings of the scenario analysis for the possible

336 use of new battery technologies in section 3.1.

337 Although less significant, battery lifetime in EV use and the share of B2U at the end of the EV use stage

338 will also influence the waste stream recycling potential in the coming years. These parameters are responsible

339 for 6 to $10 \%$ of the total variance in the waste stream recycling potential for lithium, nickel, and cobalt, and

340 for $34 \%$ in the case of copper. Longer battery lifetime in EV use and a higher share of second use at the end

341 of life will contribute to delaying the eventual return of batteries for recycling, and hence lower the potential

342 of meeting the material demands for battery production. Nevertheless, the effect of longer battery lifetime in

343 EV use and more second use at the end of first life is not always negative. In particular, the benefits of

344 reducing the demand for raw materials in stationary energy storage applications with more B2U rate for 
retired EV batteries needs to be considered as a sustainability credit for the EV value chain.

Table 1: First order Sobol indices for lithium, nickel, cobalt, and copper

\begin{tabular}{|l|c|c|c|c|}
\hline & $\begin{array}{c}\text { Lithium } \\
{[\%]}\end{array}$ & $\begin{array}{c}\text { Nickel } \\
{[\%]}\end{array}$ & $\begin{array}{c}\text { Cobalt } \\
{[\%]}\end{array}$ & $\begin{array}{c}\text { Copper } \\
{[\%]}\end{array}$ \\
\hline $\begin{array}{l}C_{i}(s), \text { Technologies average specific metal } \\
\text { content per kWh }\end{array}$ & 87 & 92 & 92 & 58 \\
\hline$\mu_{E V}$, mean battery lifetime in EV use & 5 & 3 & 3 & 17 \\
\hline $\begin{array}{l}1-S(w), \text { Second use share for retired EV } \\
\text { batteries }\end{array}$ & 4 & 2 & 2 & 2 \\
\hline $\begin{array}{l}\sigma_{E V}, \text { standard deviation of battery lifetime } \\
\text { in EV use }\end{array}$ & 1 & 1 & 1 & 3 \\
\hline$\mu_{B 2 U}$, mean battery lifetime in second use & 0 & 0 & 0 & \\
\hline
\end{tabular}

\section{Conclusion}

This study forecasts the potential contribution of EV battery recycling to fulfilling the material needs of producing EV batteries over the next 20 years. The study has shown that recycling operators need to invest in adequate battery recycling capacity during the next ten years in preparation for an exponential growth in the annual returns of EV batteries to recycling. Nevertheless, in order to avoid overcapacity in recycling facilities, it should be highlighted that the size of the waste stream may not exceed one third of the put on market product stream until 2040 should be highlighted. Future investments in battery recycling are subject

to substantial risks from the changing battery technologies used in EV models. The study shows that the put on market battery technologies will challenge the business model of recycling processes with future technologies trending to minimal or no inherent content of valuable materials. batteries is strongly dependent on the successful commercialization of cobalt-free battery technologies. On 359 the one hand, introducing advanced and beyond lithium ion technologies to the market by 2027 and then 360 dominating the sales in 2040 can significantly reduce the European EV batteries sector demand for cobalt, 361 nickel, and graphite below the level of secondary supply in 2040. In such scenario, the European EV batteries 
sector will only exploit $25 \%$ of the secondary supply, with the rest being exploited by other sectors in Europe.

363 Oppositely, scenarios with a strong dependency on cobalt-containing battery technologies yields a supply of 364 recycled materials from discarded EV batteries can cover at best $40 \%$ of the demand in 2040 .

Contrary to cobalt, nickel, and graphite, the European EV batteries sector demand for lithium and copper will continue to increase after 2020 for all scenarios due to increasing EV sales. Furthermore, the study demonstrates the importance of closed loop recycling of lithium in contrast to the current approach of open loop recycling. The potential lithium content of the EV battery waste stream in 2040 is projected to substantially exceed the entire European demand for lithium from other sectors. Hence, recycling operators need to ensure that lithium is recovered with suitable purity for battery application in order to avoid a surplus of secondary supply. Secondly, the future waste stream content of copper will not exceed half the demand needed to produce new EV batteries. In addition, open loop recycling of copper is feasible on account of the established markets for recycled copper.

The scenario based and Monte Carlo simulation based sensitivity analyses displayed a wide range of results for the waste stream recycling potential. Furthermore, the global sensitivity analysis identified the possible range of energy specific raw materials content as the uncertainty that most influences the variance of the model output. This parameter corresponds to the share of battery technologies in EV sales. To a lesser extent, assumptions for battery lifetime in EV use and the share of second use at the end of the EV stage influence the variance of the model output.

The scope of future studies may include more important battery raw materials; such as manganese, aluminium, and silicon. In addition, the recycling efficiency of different processes could be included in the forecasting model to evaluate the net secondary supply and adequate processing schemes for the evolving waste stream. Furthermore, assessment of recycled feedstock economic potential, trend analysis of raw materials price, and top-down lifecycle assessment studies based on this work can support cost accounting analysis of recycling operation and drafting extended producer responsibility schemes. 


\section{Acknowledgments}

387 This research is supported by European Union's Horizon 2020 research and innovation programme under 388 grant agreement No 814464, project Si-Drive (Silicon Alloying Anodes for High Energy Density Batteries 389 comprising Lithium Rich Cathodes and Safe Ionic Liquid based Electrolytes for Enhanced High VoltagE 390 Performance).

\section{5. References}

life analysis. Journal of Power Sources, Volume 239, pp. 9-15.

Azevedo, M. et al., 2018. Lithium and cobalt: A tale of two commodities. [Online] Available at: https://www.mckinsey.com/industries/metals-and-mining/our-insights/lithium-and-cobalt-a$\underline{\text { tale-of-two-commodities }}$

[Accessed 1410 2020].

Barré, A. et al., 2013. A review on lithium-ion battery ageing mechanisms and estimations for automotive applications. Journal of power sources, Volume 241, pp. 680-689.

Bobba, S. et al., 2018. Life Cycle Assessment of repurposed electric vehicle batteries: an adapted method based on modelling energy flows. Journal of Energy Storage, Volume 19, pp. 213-225.

Bobba, S., Mathieux, F. \& Blengini, G. A., 2019. How will second-use of batteries affect stocks and flows in the EU? A model for traction Li-ion batteries. Resources, Conservation and Recycling, Volume 145, pp. 279-291.

Bobba, S. et al., 2018. Sustainability Assessment of Second Life Application of Automotive Batteries (SASLAB): JRC Exploratory Research (2016-2017), Luxembourg: Publications Office of the European Union.

Canals Casals, L., Amante García, B. \& González Benítez, M. M., 2016. A Cost Analysis of Electric Vehicle Batteries Second Life Businesses. In: S. Capuz-Rizo, ed. Project Management and Engineering 
Research. s.1.:Springer, Cham, pp. 129-141.

411 Canals Casals, L., Barbero, M. \& Corchero, C., 2019. Reused second life batteries for aggregated demand 412 response services. Journal of Cleaner Production, Volume 212, pp. 99-108.

413 Cebulla, F. et al., 2018. How much electrical energy storage do we need? A synthesis for the U.S., Europe, 414 and Germany. Journal of cleaner production, Volume 181, pp. 449-459.

415 Chancerel, P., 2010. Substance flow analysis of the recycling of small WEEE, Berlin: Institut für 416 Technischen Umweltschutz Berlin.

419 De Haldevang, M., 2020. Coronavirus could have a lasting effect on China-dominated lithium sector. $420 \quad$ [Online]

421 Available at: https://qz.com/1812892/coronavirus-may-have-lasting-effect-on-china-dominated-lithium422 sector/

423 [Accessed 14 October 2020].

424 Debnath, U. K., Ahmad, I. \& Habibi, D., 2014. Quantifying economic benefits of second life batteries of 425 gridable vehicles in the smart grid. International Journal of Electrical Power \& Energy Systems, Volume 63, 426 pp. $577-587$.

Drabik, E. \& Rizos, V., 2018. Prospects for electric vehicle batteries in a circular economy, Brussels: European Union.

Ellingsen, L. A.-W., Singh, B. \& Strømman, A. H., 2016. The size and range effect: lifecycle greenhouse gas emissions of electric vehicles. Environmental Research Letters, 11(5), p. 054010.

Elshkaki, A., Graedek, T. E., Ciacci, L. \& Reck, B. K., 2016. Copper demand, supply, and associated energy use to 2050. Global Environmental Change, Volume 39, pp. 305-315.
European
Comission,
2018a.
European
Battery
Alliance.
[Online] 
434 Available at: https://ec.europa.eu/growth/industry/policy/european-battery-alliance_en

European Comission, 2018b. Report on Raw Materials for Battery Applications, Brussels: European Comissions.

437 European Commission, 2019. State aid: Commission approves €3.2 billion public support by seven 438 Member States for a pan-European research and innovation project in all segments of the battery value 439 chain. Brussels: s.n.

440 European Commission, 2020. COMMUNICATION FROM THE COMMISSION TO THE EUROPEAN 441 PARLIAMENT, THE COUNCIL, THE EUROPEAN ECONOMIC AND SOCIAL COMMITTEE AND THE 442 COMMITTEE OF THE REGIONS Critical Raw Materials Resilience: Charting a Path towards greater 443 Security and Sustainability. Brussels: $\operatorname{COM}(2020) 474$ final.

444 Eurostat, 2019. Sales and collection of portable batteries and accumulators. [Online] 445 Available at: https://ec.europa.eu/eurostat/web/products-datasets/-/env_waspb 446 [Accessed 08 April 2019].

447 Gattiglio, F., 2019. Panel Discussion I: The Batteries Directive Review. Lyon: 24th International Congress 448 for Battery Recycling ICBR 2019.

449 Goldie-Scot, L., 2019. A Behind the Scenes Take on Lithium-ion Battery Prices. [Online] 450 Available at: $\quad$ https://about.bnef.com/blog/behind-scenes-take-lithium-ion-battery-prices/ $451 \quad$ [Accessed 24 July 2019].

452 Herman, J. \& Usher, W., 2017. SALib: An open-source Python library for Sensitivity. Journal of Open $453 \quad$ Source Software, 2(9), p. 97.

454 IEA, 2018. Global EV Outlook 2018, Paris: International Energy Agency.

IEA, 2020. Global EV Outlook 2020, Paris: International Energy Agency.

Jenkins, D., Fletcher, J. \& Kane, D., 2008. Lifetime prediction and sizing of lead-acid batteries for microgeneration storage applications. IET Renewable Power Generation, 2(3), pp. 191-200. 
Kane, M., 2020. Global EV Sales For 2019 Now In: Tesla Model 3 Totally Dominated. [Online] 459 Available at: https://insideevs.com/news/396177/global-ev-sales-december460 2019/\#: :text=Around\%202.2\%20million\%20passenger\%20plug,which\%20makes\%20us\%20cautiously\% $461 \quad$ 20optimistic.

462 [Accessed 22 October 2020].

463 Kelleher Environmental, 2019. Research Study on Reuse and Recycling of Batteries Employed in Electric 464 Vehicles, Washington, DC: American Petroleum Institute.

Li, Z., Khajepour, A. \& Song, J., 2019. A comprehensive review of the key technologies for pure electric vehicles. Energy, Volume 182, pp. 824-839.

Mathai, A. M. \& Haubold, H. J., 2018. Collection of random variables. In: Probability and Statistics A Course for Physicists and Engineers. Berlin, Boston: De Gruyter, pp. 249-258.

Mehlhart, G., Kosińska, I., Baron, Y. \& Hermann, A., 2017. Assessment of the implementation of Directive 2000/53/EU on end-of-life vehicles (the ELV Directive) with emphasis on the end of life vehicles of unknown whereabouts, Brussels: European Commission.

Melin, H. E., 2019. State-of-the-art in reuse and recycling of lithium-ion batteries-A research review, s.1.: The Swedish Energy Agency.

Miao, Y., Hynan, P., von Jouanne, A. \& Yokochi, A., 2019. Current Li-Ion Battery Technologies in Electric Vehicles and Opportunities for Advancements. energies, 12(6), p. 1074.

Mohr, M., Peters, J., Baumann, M. \& Weil, M., 2020. Toward a cell-chemistry specific life cycle assessment of lithium-ion battery recycling processes. Journal Of Industrial Ecology, 24(6), pp. 1310-1322.

Nan, C. et al., 2011. Solvothermal synthesis of lithium iron phosphate nanoplates. Journal of Materials Chemistry, 21(27), pp. 9994-9996.

Neubauer, J., Smith, K., Wood, E. \& Pesaran, A., 2015. Identifying and Overcoming Critical Barriers to Widespread Second Use of PEV Batteries, Denver: NREL. 
2019.

About

nickel.

[Online]

483 Available

at:

https://nickelinstitute.org/about-nickel/\#03-first-use-nickel

484 [Accessed 14 October 2020].

Today, 18(5), pp. 252-264.

Olivetti, E. A., Ceder, G., Gaustad, G. G. \& Fu, X., 2017. Lithium-Ion Battery Supply Chain Considerations: Analysis of Potential Bottlenecks in Critical Metals. Joule, 1(2), pp. 229-243.

Peeters, J. R. et al., 2018. Forecasting the recycling potential based on waste analysis: A case study for recycling Nd-Fe-B magnets from hard disk drives. Journal of Cleaner Production, Volume 175, pp. 96-108. Pillot, C., 2019. The rechargeable battery market and main trends 2018-2030. Lyon: International congress for battery recycling.

Plananska, J., 2020. Touchpoints for electric mobility: Investigating the purchase process for promoting sales of electric vehicles in Switzerland. Energy Research \& Social Science, Volume 69, p. 101745.

Polák, M. \& Drápalová, L., 2012. Estimation of end of life mobile phones generation: The case study of the Czech Republic. Waste Management, 32(8), pp. 1583-1591.

Rahman, M. A., Wang, X. \& Wen, C., 2014. A review of high energy density lithium-air battery technology. Journal of Applied Electrochemistry, 44(1), pp. 5-22.

RESEARCH INTERFACES, 2018. What do we know about next-generation NMC 811 cathode?. [Online] Available at: https://researchinterfaces.com/know-next-generation-nmc-811-cathode/ [Accessed 25 January 2021].

Richa, K., Babbitt, C. W., Gaustaf, G. \& Wang, X., 2014. A future perspective on lithium-ion battery waste flows from electric vehicles. Resources, conservation, and recycling, Volume 83, pp. 63-76.

Saltelli, A. et al., 2010. Variance based sensitivity analysis of model output. Design and estimator for the total sensitivity index. Computer Physics Communications, 181(2), pp. 259-270. 
506 Sobol, I. M., 1990. On sensitivity estimation for nonlinear mathematical models. Matem. Mod., 2(1), pp. $507 \quad 112-118$

508 Transparency market research, 2020. Recycled copper market, report preview. [Online] 509 Available at: $\quad$ https://www.transparencymarketresearch.com/recycled-copper-market.html

$510 \quad$ [Accessed 16 October 2020].

511 Tsiropoulos, I., Tarvydas, D. \& Lebedeva, N., 2018. Li-ion batteries for mobility and stationary storage 512 applications-Scenarios for costs and market growth, Luxembourg: Publications Office of the European 513 Union.

514 U.S. Geological Survey, 2020. Mineral commodity summaries 2020, Reston, Virginia: U.S. Geological 515 Survey.

516 Velázquez-Martínez, O. et al., 2019. A Critical Review of Lithium-Ion Battery Recycling Processes from 517 a Circular Economy Perspective. Batteries, 5(4), p. 68.

518 Walton, B., Wu , H., Alberts, G. \& Hooper, J., 2019. New market. new entrants. new challenges. Battery 519 electric vehicles, s.l.: Deloitte LLP.

$520 \mathrm{Xu}, \mathrm{C}$. et al., 2017. Generation and management of waste electric vehicle batteries in China. 521 Environmental Science and Pollution Research, 24(26), pp. 20825-20830.

522 Yang, S., Zavalij, P. Y. \& Whittingham, M. S., 2001. Hydrothermal synthesis of lithium iron phosphate 523 cathodes. Electrochemistry Communications, 3(9), pp. 505-508.

524 Ziemann, S., Müller, D. B., Schebek, L. \& Weil, M., 2018. Modeling the potential impact of lithium 525 recycling from EV batteries on lithium demand: A dynamic MFA approach. Resources, Conservation and 526 Recycling, Volume 133, pp. 76-85. 